\title{
Oxidative Stress in Preterm Rat Brain Is Due to Mitochondrial Dysfunction
}

\author{
ROSA SÁNCHEZ-ALVAREZ, ANGELES ALMEIDA, AND JOSÉ M. MEDINA \\ Departamento de Bioquímica y Biología Molecular [R.S.A, A.A, J.M.M.], Facultad de Farmacia, \\ Universidad de Salamanca, Salamanca, Spain, and Unidad de Investigación [A.A.], Hospital Universitario \\ de Salamanca, Salamanca, Spain.
}

\begin{abstract}
Prematurity-mediated cerebral damage has been associated with oxidative stress. The aim of the present work was to study the possible role played by free oxygen radicals generated by mitochondrial respiratory function in cerebral injury in preterm neonates. Our results show that whereas total glutathione concentrations are similar in term and preterm neonates, the GSH/ GSSG ratio decreases sharply in preterm neonates immediately after birth. This effect is not due to a lack of enzymes involved in GSH regeneration, such as glutathione reductase and glucose6-phosphate dehydrogenase, but to a significant increase in freeradical generation in preterm rat brain as shown by the increase in lipoperoxidation. Because the mitochondrion is the main source of free radicals in the cell, mitochondrial respiratory function was studied in the brain of preterm neonates. Our results show that prematurity prevented the postnatal increases in complex II-III activity and ATP concentrations that occur in term
\end{abstract}

ABSTRACT

neonates at $5 \mathrm{~min}$ after delivery. All these effects were counteracted by the oxygen supply, suggesting that the inhibition of mitochondrial function is caused by restricted oxygen availability. Consequently, cerebral damage associated with prematurity may be mediated by mitochondrial free-radical generation as a consequence of hypoxia undergone by preterm neonates at birth. (Pediatr Res 51: 34-39, 2002)

\section{Abbreviations}

G6PD, Glucose-6-phosphate dehydrogenase

GPx, Glutathione peroxidase

GRd, Glutathione reductase

GSH, reduced glutathione

GSSG, oxidized glutathione

GSx, GSH $+2 \times$ GSSG concentrations

TBARS, thiobarbituric acid-reactive substances
Prematurity is an important etiopathological factor in perinatal cerebral damage (1). At present, brain injury in the premature infant is an important problem, not only because of the large number of infants affected yearly, but also because $25 \%$ to $50 \%$ of survivors exhibit developmental disabilities involving motor disturbances and mental retardation (2-5). Although the molecular mechanisms involved in cerebral damage associated with prematurity are not fully understood, recent works have proposed that free oxygen radicals could participate in the pathogenesis of this phenomenon $(1,6-8)$. In this context, a significant correlation between prematurity and free radical-mediated lipid peroxidation in preterm infants has been established (6). Moreover, during early extrauterine life the premature neonate is frequently exposed to conditions

Received April 9, 2001; accepted August 21, 2001.

Correspondence and reprint requests to: José María Medina, Departamento de Bioquímica y Biología Molecular, Universidad de Salamanca, Edificio Departamental, Plaza de los Doctores de la Reina, 37007 Salamanca, Spain; e-mail: medina@gugu.usal.es

This work was supported by grants from the DGESC (Ministerio de Ciencia y Tecnología, Spain) and from the FIS (Ministerio de Sanidad y Consumo, Spain). RS-A is a recipient of a fellowship from "Agencia Española de Cooperación Internacional," Ministerio de Asuntos Exteriores, Spain.

RSA and AA contributed equally to this work. associated with increased free radical generation, such as hypoxia $(9-11)$.

Oxidative stress is defined as the unbalance between the pro-oxidant and antioxidant mechanisms of cells in favor of the former (12). Under normal conditions, the cellular defense mechanisms that lower the levels of free oxygen radicals are able to compensate for oxidative stress. Indeed, intracellular antioxidant contents, especially glutathione concentrations, are thought to be a key factor in determining cellular vulnerability (13-15). However, when oxygen radicals are overproduced, defense mechanisms are altered and the radicals reach toxic levels, causing cell death by attacking membrane lipids, proteins, and DNA (12).

We have recently shown that mitochondrial maturation takes place in the brain immediately after birth (16), a phenomenon that appears to be related to the parallel increase of oxygen availability $(16,17)$. Because mitochondrial respiratory function is the main source of free oxygen radicals in the cell, the aim of the present work was to study whether the free radicals generated during the hypoxemia undergone by preterm neonates immediately after birth could be responsible for prematurity-mediated cerebral damage. 


\section{METHODS}

Materials. Ubiquinine-5 (coenzyme Q1) was obtained from Sigma Chemical Co. (Madrid, Spain). Cytochrome $c$ (Roche Diagnostics, Barcelona, Spain) was reduced with sodium ascorbate immediately before use and passed through the Sephadex G-25M (PD-10 columns, Pharmacia LKB, Uppsala, Sweden) to remove ascorbate. Other substrates, enzymes, coenzymes, and standard analytical laboratory reagents were purchased from Sigma Chemical Co., Boehringer or Merck (Barcelona, Spain).

Animals. Animals were obtained from the animal house of the University of Salamanca, the study being approved by this Institution. Albino Wistar rats fed on a stock laboratory diet (by wt $/ \mathrm{vol}$, carbohydrate $58.7 \%$, protein $17.0 \%$, fat $3.0 \%$, plus added salts and vitamins) and of known gestational age were used for the experiments. Virgin females weighing 225-250 g were caged overnight with males. Conception was considered to occur at 01:00 $\mathrm{h}$ and was confirmed the next morning by the presence of spermatozoa in vaginal smears. Fetuses were delivered on day 20.5 (preterm neonates) or 21.5 (term neonates) of gestation (21.7 d for full gestation) by rapid hysterectomy after cervical dislocation of the mother.

Treatment of the neonates. Immediately after delivery, term and preterm neonates were carefully wiped, their umbilical cords tied and cut, and kept in an incubator at $37^{\circ} \mathrm{C}$ under a continuous stream of water-saturated air or oxygen without feeding. All neonates were killed by decapitation at the times indicated in the figures and their whole brains were rapidly $(<2$ s) freeze-clamped in liquid nitrogen and kept frozen $\left(-20^{\circ} \mathrm{C}\right)$ until analysis.

Enzyme activity determinations. For the determination of the mitochondrial respiratory chain complex and glutathione peroxidase (EC 1.11.1.9), glutathione reductase (EC 1.6.4.2) and glucose-6-phosphate dehydrogenase (EC 1.1.1.49) activities, brains were homogenized on ice with a homogenizer (B. Braun, Model 853202, Germany) in $0.1 \mathrm{M}$ potassium phosphate buffer, $\mathrm{pH} 7.4$, to a final protein concentration of $\approx 8$ $\mathrm{mg} / \mathrm{mL}$. Enzymatic activities were determined in the homogenates using a Hitachi U2000 spectrophotometer (Hitachi Ltd, Tokyo, Japan). Complex I (NADH-CoQ1 reductase; EC 1.6.99.3) activity was measured as described in Ragan et al. (18). The activity of complex II-III (succinate-cytochrome $c$ reductase; EC 1.8.3.1) was determined following the method of King (19). Complex IV (cytochrome $c$ oxidase; EC 1.9.3.1) activity was determined as described by Wharton and Tzagoloff (20). Citrate synthase activity (EC 4.1.3.7) was measured as described by Shepherd (21). Glutathione reductase activity was determined as described by Barker (22), and glutathione peroxidase activity was determined as previously described by Wendel (23). The activity of glucose-6-phosphate dehydrogenase was determined as described by Deutsch (24). All enzyme activities were expressed as nanomoles per min per milligram of protein, except for cytochrome $c$ oxidase, which was expressed as the first-order rate constant ( $\mathrm{k}$ per min per milligram of protein).

Metabolite determinations. For glutathione measurement, homogenates were transferred to $1.5 \mathrm{~mL}$ Eppendorf tubes and centrifuged at $13,000 \mathrm{~g}$ for $5 \mathrm{~min}$ at $4^{\circ} \mathrm{C}$, and the supernatants were used for glutathione determinations. GSx (the amount of GSH plus $2 \times$ the amount of GSSG) was measured as previously described $(25,26)$. In brief, $10 \mu \mathrm{L}$ of supernatant was transferred into microtiter plate wells and diluted with $90 \mu \mathrm{L}$ of water. After the addition of $100 \mu \mathrm{L}$ of reaction mixture $(1 \mathrm{mM}$ EDTA, $0.3 \mathrm{mM}$ 5,5'-dithio-bis (2-nitrobenzoic acid), $0.4 \mathrm{mM}$ $\mathrm{NADPH}$, and $1 \mathrm{U} / \mathrm{mL}$ glutathione reductase in $0.1 \mathrm{M}$ sodium phosphate buffer, $\mathrm{pH} 7.5$ ), the increase in absorbance at $405 \mathrm{~nm}$ was monitored at 15 -s intervals for 2.5 min using a microtiter plate reader (SLT Labinstruments, Austria). GSx contents were calculated with the software provided by the plate reader using GSSG standards $(0-5 \mu \mathrm{M})$, which were treated in exactly the same way as the samples. GSSG was quantified after the derivation of GSH in $130 \mu \mathrm{L}$ of sample with $5 \mu \mathrm{L}$ of 2 -vinylpyridine (adjusted with $0.2 \mathrm{M}$ Tris to a pH between 5 and 7) for $1 \mathrm{~h}$. After this incubation, $10 \mu \mathrm{L}$ samples were assayed as described above using similarly treated GSSG standards $(0-5$ $\mu \mathrm{M})$. GSH contents were calculated from the difference: GSx $-2 x G S S G$. GSH and GSSG were expressed as nanomoles per milligram of protein.

For ATP determination, frozen brains were weighed and immediately homogenized in 30 volumes of $0.3 \mathrm{M} \mathrm{HClO}_{4}$. Extracts were neutralized with $0.5 \mathrm{M} \mathrm{KHCO}_{3}$ and centrifuged, the supernatants being used for analysis. ATP was determined by the luciferin/luciferase chemiluminescence method using a commercially available kit (Sigma Chemical Co.) and following the manufacturer's instructions.

Lipid peroxidation assays. Lipid peroxides were determined as thiobarbituric acid-reactive substances (TBARS) by the method of Yagi (27). Briefly, tissues were homogenized in 0.1 $\mathrm{M}$ phosphate buffer on ice at $\mathrm{pH} 7.4$ immediately before the assays. Tissues homogenates were centrifuged at $2700 \mathrm{~g}$ for 10 min, and the supernatant was treated twice with $1.5 \mathrm{M} \mathrm{H}_{2} \mathrm{SO}_{4}$ and $10 \%$ phosphotungstic acid and centrifuged to remove potentially interfering substances. The pellets were treated with $29 \mathrm{mM}$ thiobarbituric acid in $8.75 \mathrm{M}$ acetic acid at $95^{\circ} \mathrm{C}$ for 60 min. After cooling, the samples were extracted with n-butanol and fluorescence was measured (excitation wavelength, 515 $\mathrm{nm}$; emission wavelength, $553 \mathrm{~nm}$ ) on a fluorescence spectrophotometer (Hitachi, Model F 4010, Tokyo, Japan). In parallel, the calibration curves were obtained with malondialdehyde standards $(0-12 \mathrm{mM})$, prepared by dissolving 1,1,3,3tetraethoxypropane in water.

Protein determinations. Protein concentrations were determined in brain homogenates by the method of Lowry et al. (28), using BSA as standard.

Statistical analysis. Results are expressed as means \pm SEM for the number of neonates, indicated in the legends, coming from at least three different pregnant rats. Statistical analysis of the results was determined by $t$ test.

\section{RESULTS}

Figure 1 shows the reduced (GSH), oxidized (GSSG), and total glutathione concentrations found in the brains of term and preterm neonatal rats during the early postnatal period. At birth, preterm and term neonates showed similar concentra- 
tions of GSH. However, immediately after birth (5 min), GSH concentrations decreased rapidly in preterm neonates, the minimum value being reached at $10 \mathrm{~min}$ after delivery and increasing thereafter. At $30 \mathrm{~min}$ after birth, there were no significant differences in GSH concentrations between preterm and term neonates (Fig. 1). A concomitant increase in GSSG concentrations was observed immediately after birth, GSSG levels in preterm neonates reaching levels that were 4-fold higher that those of term neonates at $10 \mathrm{~min}$ after birth. As observed for GSH concentrations, GSSG levels in preterm neonates re-
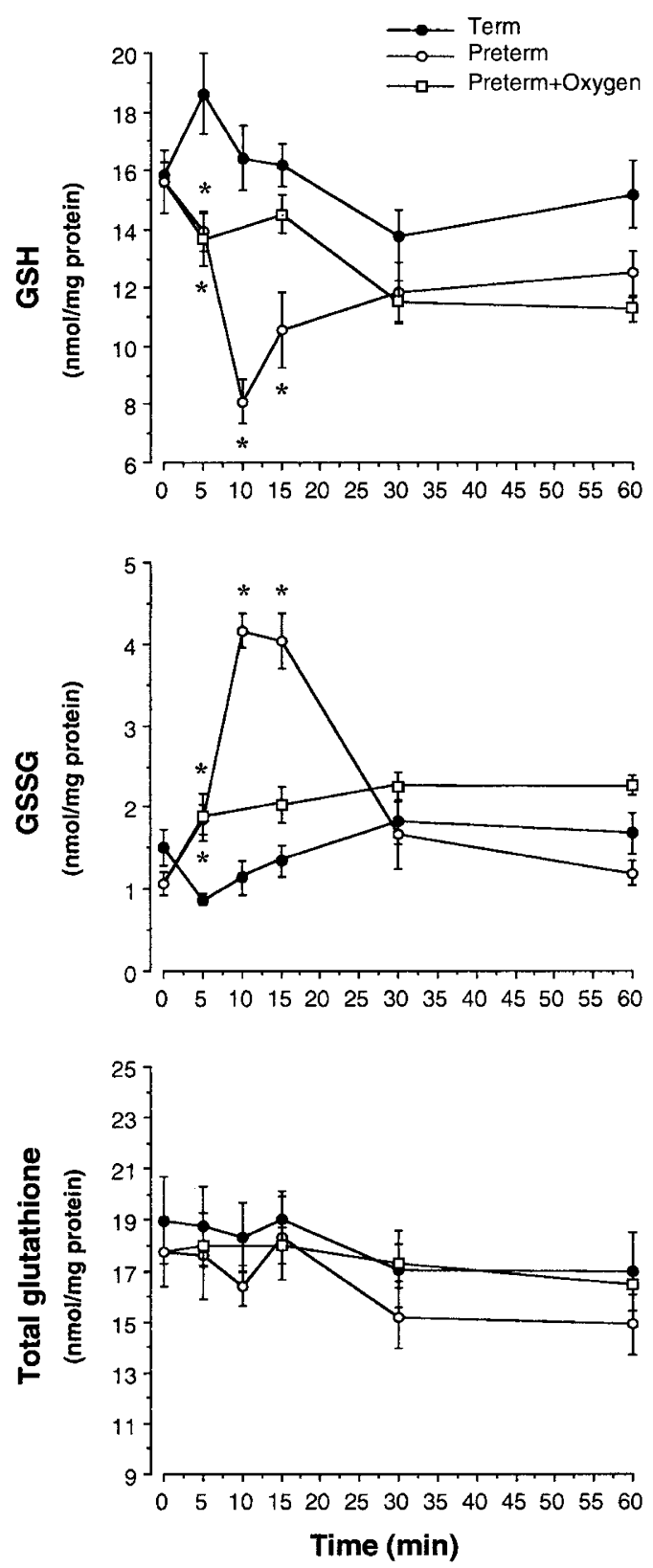

Figure 1. Glutathione concentrations in term and preterm rat brain during the early postnatal period. Term and preterm fetuses $(0 \mathrm{~h}$, without breathing) were incubated at $37^{\circ} \mathrm{C}$ under a continuous stream of water-saturated air or oxygen. After the times indicated in figure, neonates were killed and their brains were immediately removed and frozen for analysis of reduced glutathione (GSH), oxidized glutathione (GSSG), and total glutathione (GSx) concentrations. Results are means \pm SEM values from 5-10 neonates coming from 2-5 different pregnant rats. ${ }^{*} p<0.05$ compared with the term group. turned to the values of term neonates 30 min after delivery (Fig. 1). It should be noted that administration of oxygen to neonates immediately after birth prevented the changes observed in GSH and GSSG concentrations in preterm neonates, oxygen-supplemented preterm neonates showing patterns very similar to those found in term neonates (Fig. 1). On the other hand, total glutathione concentrations did not change in any of the experimental groups studied (Fig. 1), suggesting that the preterm neonatal brain has the capacity for glutathione synthesis or degradation similar to that of term neonates.

To establish whether the decrease in the GSH/GSSG ratio observed in preterm neonates after birth was due to a poor capacity for GSH regeneration, we studied the activities of the enzymes involved in the glutathione redox cycle, i.e. the activities of GPx, GRd, and G6PD. Table 1 shows that the activities of GPx, GRd, and G6PD did not change after birth (5 min) either in term or in preterm neonates. The activities of these enzymes did not change in either term or preterm neonates up to $1 \mathrm{~h}$ of extrauterine life (results not shown). However, the activities of GRd and G6PD at birth were about 30\% higher in preterm neonates than in term neonates, whereas GPx activity was similar in both experimental groups (Table 1).

Recent works have suggested that brain injury associated with prematurity is due, at least in part, to a higher vulnerability of the immature brain to free-radical attack $(1,6-8)$. Because the changes in GSH and GSSG concentrations observed in the brains of preterm neonates appear to be a consequence of the oxidative stress generated, we were prompted to study possible free-radical generation in the brains of preterm neonates during the early postnatal period. Figure 2 shows the concentrations of lipid peroxides [determined as TBARS (27)], a well known index of free-radical generation $(27,29,30)$, in the brains of term and preterm neonates. Immediately after birth (5 min), a significant increase in lipid peroxide concentrations in preterm and term neonates was observed. However, whereas these values decreased in term neonates at $15 \mathrm{~min}$ after birth, lipid peroxidation remained high in preterm neonates up to at least $30 \mathrm{~min}$ after birth (Fig. 2). In contrast, when preterm neonates were breathing an atmosphere of oxygen, lipid peroxide concentrations were very similar to those found in term neonates (Fig. 2).

We have recently shown (16) that the maturation of brain mitochondria occurs immediately after birth in the rat, coinciding with the enhancement in oxygen availability $(10,11)$. Because mitochondrial function is the main source of freeradical generation under certain neuropathologic circumstances

Table 1. Activities of glutathione peroxidase (GPx), glutathione reductase (GRd) and glucose-6-phosphate dehydrogenase (G6PD) in the brains of preterm or term neonatal rats

\begin{tabular}{lrcrrr}
\hline & \multicolumn{2}{c}{ Neonate $(0 \mathrm{~h})$} & & \multicolumn{2}{c}{ Neonate $(5 \mathrm{~min})$} \\
\cline { 2 - 3 } \cline { 5 - 6 } & \multicolumn{1}{c}{ Term } & \multicolumn{1}{c}{ Preterm } & & \multicolumn{1}{c}{ Term } & \multicolumn{1}{c}{ Preterm } \\
\hline GPx & $189.9 \pm 8.9$ & $199.3 \pm 9.4$ & & $189.2 \pm 8.6$ & $187.9 \pm 6.3$ \\
GRd & $7.4 \pm 0.7$ & $11.2 \pm 1.1^{*}$ & & $6.2 \pm 0.4$ & $10.9 \pm 0.4^{*}$ \\
G6PD & $23.9 \pm 1.6$ & $33.5 \pm 1.8^{*}$ & & $23.8 \pm 1.7$ & $31.6 \pm 1.9^{*}$ \\
\hline
\end{tabular}

Results are means \pm SEM values from 5-14 neonates coming from 3-4 different pregnant rats and are expressed as $\mathrm{nmol} / \mathrm{min} / \mathrm{mg}$ protein. ${ }^{*} p<0.05$ as compared to the term group. 


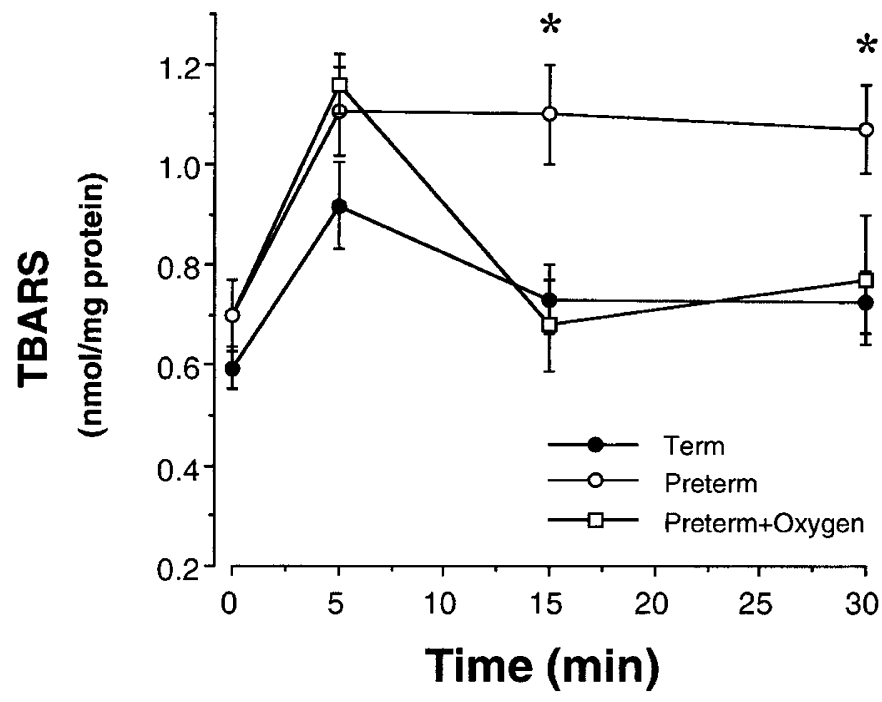

Figure 2. Lipids peroxide concentrations, measured as thiobarbituric acidreactive substances (TBARS), in the brain of term and preterm neonatal rats during the early postnatal period. Term and preterm fetuses $(0 \mathrm{~h}$, without breathing) were incubated at $37^{\circ} \mathrm{C}$ under a continuous stream of watersaturated air or oxygen. After the times indicated in figure, neonates were killed and their brains were immediately removed and frozen for TBARS analysis. Results are means \pm SEM values from 9-13 newborns coming from 2-3 different pregnant rats. ${ }^{*} p<0.05$ compared with the term group.

such as a deficit in cerebral oxygen supply $(12,31,32)$, and because preterm neonatal rats undergo hypoxemia possibly due to a deficit in lung surfactant (11), we studied the possible role of mitochondrial function in prematurity-mediated free-radical generation. Figure 3 shows the mitochondrial respiratory chain complex activities in the brains of term and preterm neonatal
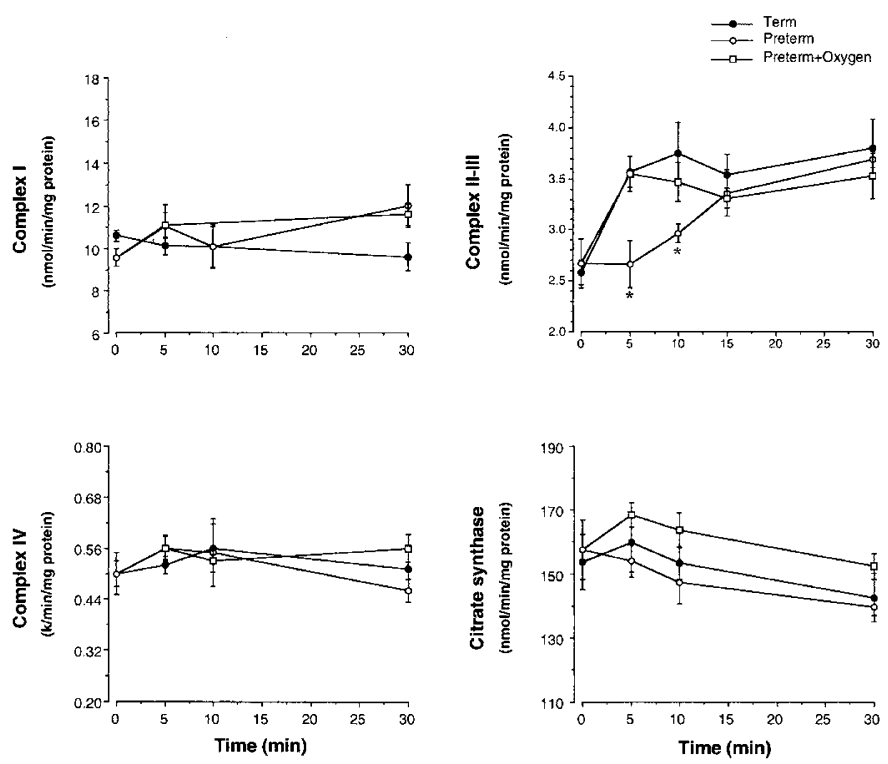

Figure 3. Mitochondrial respiratory chain complex activities in the brains of term and preterm neonatal rats during the early postnatal period. Term and preterm fetuses $\left(0 \mathrm{~h}\right.$, without breathing) were incubated at $37^{\circ} \mathrm{C}$ under a continuous stream of water-saturated air or oxygen. After the times indicated in figure, neonates were killed and their brains were immediately removed and frozen for enzymatic analysis. Results are means \pm SEM values from 4-15 newborns coming from $3-5$ different pregnant rats. $* p<0.05$ compared with the term group. rats during the early postnatal period. In agreement with our previous results (16), immediately after birth (5 min), complex II-III activity increased by about $30 \%$, whereas complex I, complex IV, and citrate synthase activities remained unchanged, suggesting that mitochondrial maturation occurs immediately after birth. However, the postnatal increase in complex II-III activity was absent in preterm neonates up to $15 \mathrm{~min}$ of extrauterine life. The activities of complex I, complex IV, and citrate synthase in preterm neonates were similar to those found in term neonates (Fig. 3), suggesting that changes in complex II-III activity between preterm and term neonates would not be due to differences in the number of mitochondria. Additionally, when preterm neonates were treated with oxygen during the early postnatal period, complex II-III activity increased sharply $(27 \%)$ after birth, showing a developmental profile similar to that found in term neonates (Fig. 3).

The activities of glycolytic enzymes are very low in the rat brain at birth (33-35), and hence, mitochondrial function is the main source of ATP synthesis for the neonatal rat brain (16). In this work, the concentrations of ATP in the brains of preterm neonates were measured during the first hour of extrauterine life. Unlike term neonates, in which a postnatal increase (30\%) in ATP concentrations was observed, preterm neonates showed a significant $(50 \%, p<0.05)$ decrease in ATP levels at 5 min after birth (Fig. 4), although they increased thereafter up to 15 min after birth, when term values were reached. However, the administration of oxygen to preterm neonates prevented the decrease in ATP concentrations, with ATP levels very similar to those found in term neonates being observed (Fig. 4).

Figure 5 shows the effect of oxygen administration on postnatal mortality in neonates during the early postnatal period. As shown, oxygen treatment to preterm neonates totally

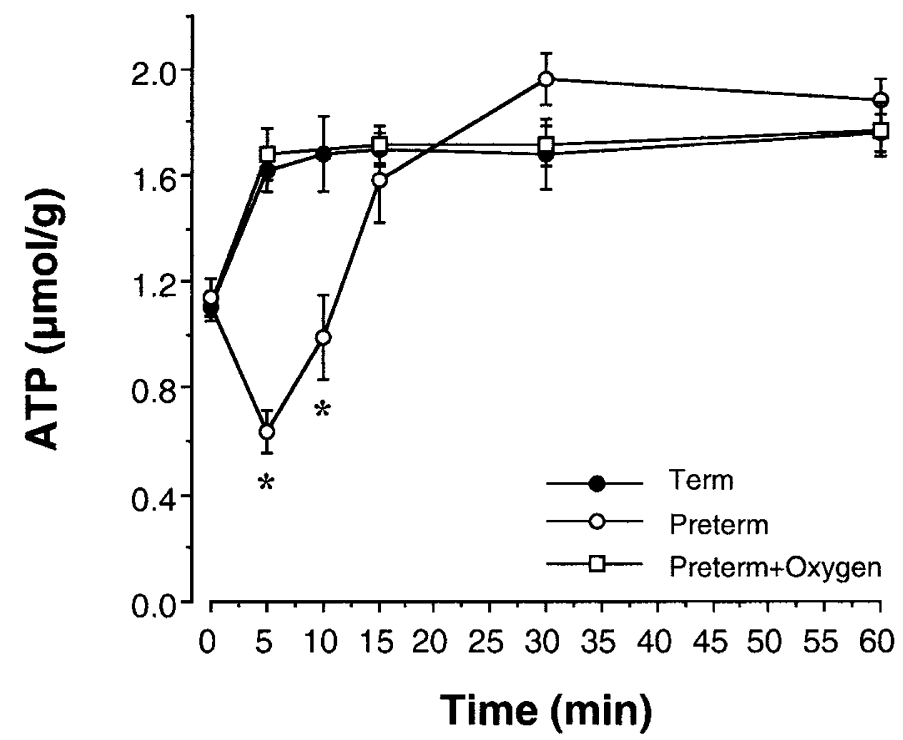

Figure 4. ATP concentrations in the brains of term and preterm neonatal rats during the early postnatal period. Term and preterm fetuses $(0 \mathrm{~h}$, without breathing) were incubated at $37^{\circ} \mathrm{C}$ under a continuous stream of watersaturated air or oxygen. After the times indicated in figure, neonates were killed and their brains were immediately removed and frozen for ATP analysis. Results are means \pm SEM values from $6-15$ newborns coming from 2-6 different pregnant rats. ${ }^{*} p<0.05$ compared with the term group. 


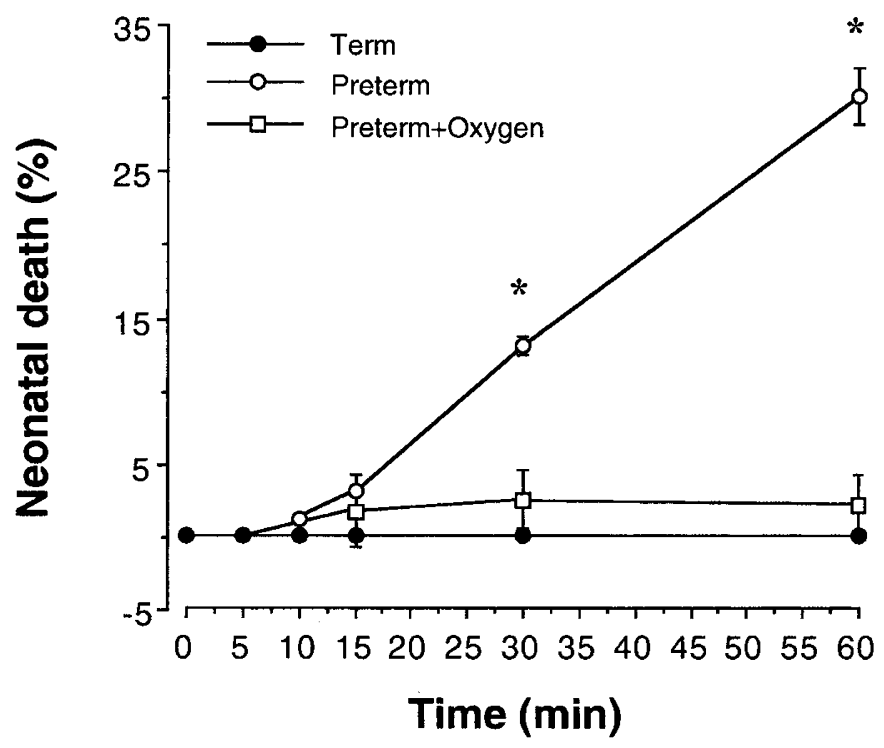

Figure 5. Effect of prematurity on neonatal mortality during the early postnatal period. Term and preterm neonates $(0 \mathrm{~h}$, without breathing) were incubated at $37^{\circ} \mathrm{C}$ under a continuous stream of water-saturated air or oxygen during at least $60 \mathrm{~min}$. Values are means \pm SEM from 9-15 newborns coming from 2-6 different pregnant rats and are expressed as percentages of dead neonates in relation to total neonates from each litter. ${ }^{*} p<0.05$ compared with the term group.

prevented the postnatal mortality found in untreated-preterm neonates, whose percentages of death were very similar to those found for term neonates.

\section{DISCUSSION}

Oxidative stress has been proposed to be a important factor involved in brain injury associated with prematurity $(1,36)$. In fact, studies in premature human infants during the neonatal period suggest a propensity to generate free radicals $(6,7,37)$. Our results show that prematurity is associated with a $50 \%$ decrease in GSH concentrations and a concomitant 4-fold increase in GSSG contents in neonatal brain (Fig. 1) at $10 \mathrm{~min}$ after birth, with no changes in total glutathione concentrations. These changes in glutathione oxidation were not due to a deficit of the enzymes involved in the glutathione redox cycle, because glutathione peroxidase and glutathione reductase activities were very similar to those found in term neonates (Table 1). In addition, the activity of glucose-6-phosphate dehydrogenase, a key enzyme in the pentose phosphate pathway that generates NADPH to restore GSH levels (38), was even higher in preterm neonates than that found in brain from term neonates. Nevertheless, these results suggest that oxidative stress occurs in the brains of preterm neonates, probably contributing to prematurity-mediated brain injury. In agreement with this suggestion, we observed an important increase in lipid peroxidation in preterm neonates (Fig. 2) after birth, which remained high up to $30 \mathrm{~min}$ of extrauterine life. This result indicates that there is an increase in free-radical generation in the brains of preterm neonates that might be responsible for the changes observed in the GSH/GSSG ratio (Fig. 1). Oxidative stress in preterm neonates seems to be associated with a deficit in cerebral oxygen supply because the adminis- tration of oxygen to preterm neonates at birth prevented the postnatal decrease in GSH concentrations and the increases in GSSG levels (Fig. 1) and lipid peroxidation (Fig. 2) observed in untreated-preterm neonates. It has been described that preterm neonates undergo hypoxemia after birth (11). Thus, preterm neonatal rats show lower $\mathrm{PO}_{2}$ levels during the first two hours of extrauterine life as compared with neonatal rats at term. This fact correlates with the observed lung phospholipid concentrations and is consistent with the idea that the hypoxemia observed in preterm rats would be due to a deficit in lung surfactant (11). Therefore, the rat model might be a useful tool for the study respiratory distress syndrome in preterm human babies.

Free radicals are generated by a number of metabolic reactions in the brain, particularly those occurring during cellular respiration. In fact, mitochondrial respiratory function produces oxygen free radicals at rates that depend on the redox state of mitochondrial respiratory chain components, the ubisemiquinone autoxidation being the main step in producing superoxide anion $(31,32,39)$. Recently, we have shown that mitochondrial maturation in the brain occurs immediately (5 min) after birth, as shown by the sharp increase in the activity of complex II-III and the concomitant increase in cerebral ATP levels (16). Interestingly, our results show that prematurity avoided both the early postnatal increase in complex II-III activity and ATP concentrations, suggesting that mitochondrial maturation is delayed in preterm neonates (Figs. 3 and 4). This mitochondrial dysfunction correlated with the postnatal increase in lipid peroxide concentrations (Fig. 2), suggesting that the impairment in the activity of complex II-III could contribute to free radical generation observed in the brains of preterm neonates (Fig. 2). Indeed, an impairment in electron flow at the cytochrome bc1 region (40) and oxidation of ubisemiquinone $(31,32,39,41,42)$ are the main mitochondrial respiratorychain steps that generate oxygen free radicals. In fact, experimental inhibition of complex II-III with antimycin sharply increased superoxide anion production by mitochondria (31). In agreement with this, when the activity of complex II-III and ATP concentrations were reestablished in preterm neonates by oxygen administration at birth (Figs. 3 and 4), the increase in lipid peroxide concentrations was totally abolished (Fig. 2). These results suggest that the dysfunction of complex II-III would be responsible for the oxidative stress found in our experimental conditions.

The postnatal increase in complex II-III activity appears to be associated with a postnatal increase in oxygen availability to the brain, a process that occurs immediately after birth in term neonates $(10,11)$. Accordingly, preterm neonates only showed complex II-III activity values similar to that of term neonates when oxygen availability was increased experimentally (Fig. 3). In agreement with this finding, the increase in complex II-III activity is prevented when term neonates undergo a hypoxic episode at birth (17), all suggesting that the sharp increase in oxygen availability that occurs immediately after delivery (11) triggers mitochondrial maturation in the brain through the enhancement of complex II-III activity. Because the enhancement of complex II-III activity brought about by the increase in oxygen availability to the brain is very fast, it 
may be concluded that this effect would due to a change in the conformational state of the complex rather than to an increase in protein synthesis.

Our results suggest that prematurity causes a delay in postnatal mitochondrial maturation in the brain, preventing the increase in the cerebral energy status that occurs after birth. These changes appear to be related to the hypoxemia undergone by preterm neonates during early extrauterine life. Because mitochondrial dysfunction, particularly in complex II-III activity, seems to be the factor responsible for oxidative stress, prematurity-mediated cerebral damage could be caused by free oxygen radical production associated with the hypoxia undergone by preterm neonates.

It is well known that the time-course of human brain development differs from that of the rat. However, both humans and rats are nonprecocious species because their brain development takes place postnatally (43). In addition, both humans (44) and rats (11) undergo respiratory distress after birth as a consequence of a deficit in lung surfactant levels. It could therefore be suggested that the oxidative stress observed in preterm neonatal rats could also occur in preterm babies (6). However, whether the effect of oxidative stress on the brain of human babies is similar to that observed in the rat remains to be elucidated.

\section{REFERENCES}

1. Volpe JJ 1998 Brain injury in the premature infant: overview of clinical aspects, neuropathology and pathogenesis. Semin Pediatr Neurol 5:135-151

2. Volpe JJ 1997 Brain injury in the premature infant: Neuropathology, clinical aspects and pathogenesis. MRDD Res Rev 3:3-12

3. Hack M, Friedman H, Avroy A, Fanaroff MB 1996 Outcomes of extremely low birth weight infants. Pediatrics 98:931-937

4. Powls A, Botting N, I CRW, Stephenson G, Marlow N 1997 Visual impairment in very low birthweight children. Arch Dis Child 76:F82-F87

5. Schendel DE, Stockbauer JW, Hoffman HJ, Herman AA, Berg CJ, Schramm WF 1997 Relation between very low birth weight and developmental delay among preschool children without disabilities. Am J Epidemiol 146:740-749

6. Varsila E, Pitkanen O, Hallman M, Andersson S 1994 Immaturity-dependent free radical activity in premature infants. Pediatr Res 36:55-59

7. Lackmann GM, Hesse L, Tollner U 1996 Reduced iron-associated antioxidants in premature newborns suffering intracellular hemorrhage. Free Radic Biol Med 20:407409

8. Ditelberg JS, Sheldon RA, Epstein CJ, Ferriero DM 1996 Brain injury after perinatal hypoxia-ischemia is exacerbated in copper/zinc superoxide dismutase transgenic mice. Pediatr Res 39:204-208

9. Flamm ES, Demopoulos HB, Seligman ML, Poser RG, Ransohoff J 1978 Free radicals in cerebral ischemia. Stroke 9:445-447

10. Medina JM, Cuezva JM, Mayor F 1980 Non-gluconeogenic fate of lactate during the early neonatal period in the rat. FEBS Lett 114:132-134

11. Juanes MC, Arizmendi C, Medina JM 1986 Attenuation of postnatal hypoxia in the premature newborn rat by maternal treatment with dexamethasone: its relationship with lung phospholipid content. Biol Neonate 50:337-344

12. Halliwell B 1992 Reactive oxygen species and the central nervous system. J Neurochem 59:1609-1623

13. Ben-Yoseph O, Boxer PA, Ross BD 1996 Assessment of the role of the glutathione and pentose phosphate pathways in the protection of primary cerebrocortical cultures from oxidative stress. J Neurochem 66:2329-2337

14. Barth A, Bauer R, Gedrange T, Walter B, Linss C, Klinger W 1998 Influence of hypoxia and hyperthermia upon peroxidative and glutathione status in growthrestricted newborn piglets. Exp Toxicol Pathol 50:31-33

15. Levonen AL, Lapatto R, Saksela M, Raivio KO 2000 Expression of $\gamma$-glutamylcysteine synthetase during development. Pediatr Res 47:266-270
16. Almeida A, Bolaños JP, Medina JM 1999 Nitric oxide mediates brain mitochondrial maturation immediately after birth. FEBS Lett 452:290-294

17. Bolaños JP, Almeida A, Medina JM 1998 Nitric oxide mediates brain mitochondrial damage during perinatal anoxia. Brain Res 787:117-122

18. Ragan CI, Wilson MT, Darley-Usmar VM, Lowe PN 1987 Subfractionation of mitochondria and isolation of the proteins of oxidative phosphorylation. In: DarleyUsmar VM, Rickwood D Wilson MT (eds) Mitochondria. A Practical Approach. London, IRL Press, pp 79-112

19. King TE 1967 Preparation of succinate cytochrome $\mathrm{c}$ reductase and the cytochrome b-c1 particle, and reconstitution of succinate cytochrome c reductase. Methods Enzymol 10:216-225

20. Wharton DC, Tzagoloff A 1967 Cytochrome oxidase from beef heart mitochondria Methods Enzymol 10:245-250

21. Shepherd JA, Garland PB 1969 Citrate synthase from rat liver. Methods Enzymol 13:11-19

22. Barker JE, Bolaños JP, Land JM, Clark JB, and Heales SJR 1996 Glutathione protects astrocytes from peroxynitrite-mediated mitochondrial damage: implications for neuronal/astrocytic trafficking and neurodegeneration. Dev Neurosci 18:391-396

23. Wendel A 1981 Glutathione peroxidase. In: Lowenstein JM (ed) Methods in Enzymology, Vol 77. New York, Academic Press, pp 325-332

24. Deutsch J 1983 D-Glucose-6-phosphate dehydrogenase. In: Bergmeyer J, GraßI M (eds) Methods of Enzymatic Analysis, Vol 3. Weinheim, Verlag Chemie GmbH, pp 190-197

25. Tietze F 1969 Enzyme method for quantitative determination of nanogram amounts of total and oxidized glutathione: application to mammalian blood and other tissues. Anal Biochem 27:502-522

26. Dringen R, and Hamprecht B 1996 Glutathione content as an indicator for the presence of metabolic pathways of amino acids in astroglial cultures. J Neurochem 67:1375-1382

27. Yagi K 1984 Assay for blood plasma or serum. Methods Enzymol 105:328-330

28. Lowry OH, Rosebrough NJ, Lewis-Farr A, Randall RJ 1951 Protein measurement with the Folin phenol reagent. J Biol Chem 193:265-275

29. Barth A, Bauer R, Kluge H, Gedrange T, Walter B, Klinger W, Zwiener U 1995 Brain peroxidative and glutathione status after moderate hypoxia in normal weight and intra-uterine growth-restricted newborn piglets. Exp Toxicol Pathol 47:139-147

30. Tan S, Zhou F, Nielsen VG, Wang Z, Gladson CL, Parks DA 1998 Sustained hypoxia-ischemia results in reactive nitrogen oxygen species production and injury in the premature fetal rabbit brain. J Neupathol Exp Neurol 57:544-553

31. Boveris A, Cadenas E 1975 Mitochondrial production of superoxide anions and its relationship to the antimycin-insensitive respiration. FEBS Lett 54:311-314

32. Boveris A, Cadenas E, Stoppani OM 1976 Role of ubiquinone in the mitochondrial generation of hydrogen peroxide. Biochem J 156:435-444

33. Land JM, Booth RFG, Berger R, Clark JB 1977 Development of mitochondrial energy metabolism in rat brain. Biochem J 164:339-348

34. Wilbur DO, Patel MS 1974 Development of mitochondrial pyruvate metabolism in rat brain. J Neurochem 22:709-715

35. Leong SF, Clark JB 1984 Regional enzyme development in rat brain. Enzymes of energy metabolism. Biochem J 218:139-145

36. Sullivan JL 1988 Iron, plasma antioxidants, and the oxygen radical diseases of prematurity. Am J Dis Child 142:1341-1344

37. Lubec G, Widness JA, Hayde M, Menzel D, Pollak A 1997 Hydroxyl radical generation in oxygen-treated infants. Pediatrics 100:700-704

38. García-Nogales P, Almeida A, Fernández E, Medina JM, Bolaños JP 1999 Induction of glucose-6-phosphate dehydrogenase by lipopolysaccharide contributes to preventing nitric oxide-mediated glutathione depletion in cultured rat astrocytes. J Neurochem $72: 1750-1758$

39. Cadenas E, Boveris A, Ragan CI, Stoppani AOM 1977 Production of superoxide radicals and hydrogen peroxide by $\mathrm{NADH}$-ubiquinone reductase and ubiquinolcytochrome c reductase from beef-heart mitochondria. Arch Biochem Biophys 180:248-257

40. Poderoso JJ, Carreras MC, Lisdero C, Riobó N, Schöper F, Boveris A 1996 Nitric oxide inhibits electron transfer and increases superoxide radical production in rat heart mitochondria and submitochondrial particles. Arch Biochem Biophys 328:85-92

41. Poderoso JJ, Carreras MC, Schöpfer F, Lisdero C, Riobó N, Giulivi C, Boveris AD, Boveris A, Cadenas E 1999 The reaction of nitric oxide with ubiquinol: kinetic properties and biological significance. Free Radic Biol Med 26:925-935

42. Poderoso JJ, Lisdero C, Schöpfer F, Riobó N, Carreras MC, Cadenas E, Boveris A 1999 The regulation of mitochondrial oxygen uptake by redox reactions involving nitric oxide and ubiquinol. J Biol Chem 274:37709-37716

43. Dobbing J, Sands J 1979 Comparative aspects of the brain growth spurt. Early Hum Devel 3:79-84

44. Kotecha S 2000 Lung growth: implications for the newborn infant. Arch Dis Child Fetal Neonatal Ed 82:F69-F74 